\title{
ANALISA RUANG PUBLIK KORIDOR JALAN RATULANGI DI MAKASSAR
}

\author{
Haryanto Andi Halim ${ }^{1}$ Abd. Azis Alimuddin ${ }^{2}$ \\ 1,2 Jurusan Arsitektur Universitas Muslim Indonesia
}

\begin{abstract}
Abstrak
Kawasan jalan Ratulangi Kota Makassar dulunya merupakan jalan penghubung antara Kerajaan Tallo di bagian Utara dan Kerajaan Gowa di bagian Selatan, kawasan ini masih ditemui bangunan-bangunan bersejarah, kawasan ini menjadi lingkungan perkantoran, perdagangan dan jasa serta komersial. Lalu-lintas pada kawasan Ratulangi cukup ramai, ditunjang dengan prasarana jalan yang cukup baik, jenis kendaraan yang lewat cukup bervariasi, oleh karena itu jam kerja pada kawasan ini sangat padat, sedangkan fasilitas elemen kota di kawasan ini masih kurang dan tidak layak dilihat dari segala aktivitas kota yang terjadi di kawasan ini. Tujuan dari penelitian ini adalah menganalisa keberadaan fungsi-fungsi ruang terbuka pada bangunan yang berada disepanjang koridor jalan, pada bagian ini akan dipilih beberapa titik berdasar pada fungsi bangunan, ruang terbuka dan lokasinya terhadap jalan ratulangi, mendapatkan fungsi bangunan dan pendukung aktivitas yang terjadi disepanjang koridor jalan Ratulangi, sebagai solusi terhadap permasalahan yang ada.

Penelitian ini mengunakan teori sirkulasi, jalur pedestrian, dan activity support dari Hamid Shirvani dalam bukunya The Urban Design Process. Penulis menggunakan metode pengumpulan data observasi dan dokumentasi sedangkan metode analis datanya kualitatif fenomologis. Isu utama yang memusatkan perhatian pada makna dan pengalaman subjek sehari-hari yang bertujuan untuk menjelaskan bagaimana objek dan pengalaman tercipta secara penuh makna dan dikomunikasikan dalam kehidupan sehari-hari, perlakuan subjektivitas sebagai topik penelitian itu sendiri. Penelitian ini diharapkan memberi manfaat, agar penataan kota khususnya koridor jalan dapat tertata dengan baik sesuai dengan standar elemen kota.
\end{abstract}

\section{Kata Kunci :Ruang terbuka, Activity support, Koridor}

\section{PENDAhuluan}

Ruang publik (public space) dapat menciptakan karakter kota, dan pada umumnya memiliki fungsi interaksi sosial bagi masyarakat, kegiatan ekonomi rakyat dan tempat interaksi apresiasi budaya. Ruang publik yang menarik akan selalu dikunjungi oleh masyarakat luas dengan berbagai tingkat kehidupan sosial-ekonomi-etnik, tingkat pendidikan, perbedaan umur, dan motivasi atau tingkat kepentingan yang berlainan. Siapapun tanpa membedakan, anak, dewasa atau orang tua, kaya atau miskin, berpendidikan tinggi atau rendah, bos atau bawahan dapat memanfaatkan ruang publik kota untuk segala macam kegiatan baik individual ataupun berkelompok, kebebasan bagi rakyat melakukan kegiatan itulah kadang-kadang perlu pengendalian, perlu pengaturan fungsi-fungsi ruang, sirkulasi lalulintas dan parkir kendaraan bermotor, penempatan para pedagang kaki lima dan sebagainya.

Untuk mendapatkan fungsi yang efektif terhadap suatu lingkungan adalah adanya perbedaan area, masing-masing mempunyai perbedaan fasilitas satu sama lain yang saling menunjang. Pembentukan fungsi merupakan tujuan dari pembangunan yang dilakukan sebagai pemenuhan kebutuhan terhadap kegiatan yang dilakukan oleh manusia, standar dan panduan perencanaan merupakan alat untuk menetralisir terwujudnya massa dan ruang agar aktivitas manusia dapat berlangsung.
Fungsi koridor sebagai (linkage) penghubung dan generator tidak lepas dari pengaturan sirkulasi dan parkir (Shirvani; 1985). Dengan sirkulasi yang jelas dan nyaman akan memberikan kemudahan dan keamanan bagi para pemakainya, namun hal ini harus ditunjang dengan penataan ruang parkir yang baik agar sirkulasi yang terjadi pada koridor berjalan dengan lancar. Koridor yang mampu memberikan kejelasan, kenyamanan dan keamanan kepada para pemakainya untuk mencapai tujuan perjalanan akan menjadi ruang yang manusiawi. Koridor sebagai ruang pergerakan (sirkulasi) memiliki dua pengaruh langsung pada kualitas lingkungan, yaitu kelangsungan aktivitas komersial dan kualitas visual yang kuat terhadap struktur dan bentuk fisik kota.

Perkembangan suatu kota dengan aktivitas kegiatan manusia membuat fungsi-fungsi elemen kota dan sarana transportasi mempunyai kedudukan penting, sehingga menyebabkan pejalan kaki semakin tergeser perannya. Lebih memprihatinkan lagi ketika ruang sirkulasi pejalan kaki digunakan untuk kegiatan lain misalnya untuk tempat parkir kendaraan bermotor (on street parking) dan tempat berjualan pedagang kaki lima (activity support). Timbulnya kegiatan tersebut karena adanya interaksi dengan pejalan kaki dan adanya ruang yang memberikan peluang kegiatan tersebut. Jadi ruang sirkulasi pejalan kaki merangsang timbulnya kegiatan-kegiatan lain seperti pedagang kaki lima (sektor informal) dan tempat parkir (on street parking). Sebagai kegiatan pendukung (activity 
support) yaitu semua kegunaan (uses) dan aktivitas yang membantu terbentuknya ruang publik kota (urban public space) bentuk lokasi dan karakteristik dari area spesifik yang mencerminkan fungsi khusus penggunaan dan aktivitas. Integrasi dan koordinasi pola kegiatan merupakan hal yang penting dalam pembentukan aktivitas pendukung, berbagai pusat aktivitas yang terkoordinir terjadi pada ligkungan fisik akan menjadikan kita seperti berjalan dari satu tempat ke tempat yang lain (Spreigen, 1965).

Salah satu bagian dari kawasan Kota Makassar yang merupakan daerah dengan perkembangan yang cukup signifikan adalah koridor Jalan Ratulangi yang merupakan salah satu akses utama Kota Makassar. Koridor jalan ini memiliki potensi yang kuat sehingga memicu tumbuh dan berkembangnya berabagai macam activity support di sepanjang koridor jalan.

Keberadaan sektor perdagangan dan jasa (sektor formal) sangat kuat juga diikuti dengan sektor informal (pedagang kaki lima), kehadiran sektor informal menempati jalur-jalur strategis yang dilalui jalur pejalan kaki, hal ini menimbulkan konflik keruangan, apalagi diperparah dengan parkir kendaraan di pinggir jalan dengan berkembangnya pertokoan akibat aktivitas perbelanjaan pertokoan sepanjang jalan Ratulangi yang tidak mampu menampung kendaraan karena sempitnya lahan parkir, disamping itu pergantian moda transportasi yang terjadi di kawasan ini, menimbulkan kemacetan karena kurang dilengkapinya prasarana dan sarana yang baik sesuai dengan standar pelayanan suatu kota.

\section{Koridor (Corridor)}

Koridor sebagai ruang pergerakan (sirkulasi) dan parkir memiliki pengaruh langsung pada kualitas lingkungan, yakni kelangsungan aktivitas komersial dan kualitas visual yang kuat terhadap struktur dan bentuk fisik kota. Koridor adalah lahan yang memanjang dan membelah kota / kawasan atau sebuah lorong yang membentuk fasade bangunan berderet dengan lantai atau ruang kota, bergerak dari satu ruang ke ruang lainnya. Koridor bersifat alami seperti sungai yang membelah kota, koridor yang erat kaitannya dengan arsitektur kota adalah jalan atau transportasi didalam kota, spesifikasi dan karakteristik bangunannya pada suatu koridor jalan sangat besar pengaruhnya dalam menentukan wajah dan bentuk koridor itu sendiri.

\section{Parkir (Parking)}

Menurut Shirvani $(1985 ; 24,25)$ beberapa cara dalam mengendalikan parkir:

- Struktur tempat parkir tidak boleh mengganggu aktivitas disekitarnya, mendukung kegiatan street level dan menambah kualitas visual lingkungan, lebih baik jika pembangunannya diiringi dengan penegakan peraturan parkir yang sesuai sebagai bagian perencanaan.
- Memaksimalkan penggunaan tempat parkir dengan pelaku dan waktu yang berbeda secara simultan.

- Tempat parkir khusus dimana perusahaan atau instansi yang memiliki sejumlah besar karyawan dengan keberadaannya membutuhkan area parkir tersendiri yang memadai.

- Tempat parkir di kawasan pinggir kota yang dibangun oleh swasta dan atau pemerintah.

\section{Pendukung Aktivitas (Activity Support)}

Menurut Shirvani (1984) activity support termasuk didalamnya semua fungsi dan kegiatan yang memperkuat ruang-ruang publik kota, antara aktivitas dan ruang fisik selalu saling melengkapi. Bentuk, lokasi, dan karakter suatu tempat spesifik akan menarik munculnya fungsi, penggunaan ruang dan aktivitas yang spesifik pula. Sebaliknya suatu kegiatan cenderung memperhatikan lokasi yang layak dan baik untuk mendukung kegiatan itu sendiri. Dalam hubungannya dengan perancangan kota, activity support ini berarti suatu elemen kota yang mendukung dua atau lebih pusat kegiatan umum yang berada di kawasan pusat kota yang mempunyai konsentrasi pelayanan yang cukup besar.

Pendukung kegiatan tidak hanya menyediakan jalur pedestrian atau plaza tapi juga mempertimbangkan fungsi utama dan penggunaan elemen-elemen kota yang dapat menggerakkan aktivitas. Termasuk pusat perbelanjaan, taman rekreasi, pusat perkantoran, perpustakaan umum, dan lain-lain (Shirvani; 1985).

\section{Ruang Publik (Public Space)}

Secara spasial ruang publik didefinisikan sebagai tempat dimana setiap orang memiliki hak untuk memasukinya tanpa harus membayar uang masuk atau uang lainnya. Ruang publik dapat berupa jalan (termasuk pedestrian), tanah perkerasan (pavement), public squares, dan taman (park). Hal ini berarti bahwa ruang terbuka hijau (open space) publik seperti jalan dan taman serta ruang terbuka non-hijau publik seperti tanah perkerasan (plaza) dan public squares dapat difungsikan sebagai ruang publik. Secara esensial ruang publik mempunyai kriteria:

- Dapat memberi makna atau arti bagi masyarakat setempat secara individual maupun kelompok (meaningful).

- Tanggap terhadap semua keinginan pengguna dan dapat mengakomodir kegiatan yang ada pada ruang publik tersebut (responsive).

- Dapat menerima kehadiran berbagai lapisan masyarakat degan bebas tanpa ada diskriminasi (democratic).

\section{METODE PENELITIAN}

Metode penelitian yang digunakan adalah metode penelitian kualitatif, karena kondisi penelitian yang dilakukan adalah kondisi yang alamiah atau 
dilakukan pada obyek yang alamiah dan berkembang apa adanya, tidak ada rekayasa atau manipulasi oleh peneliti, keberadaan penelitian tidak mempengaruhi fenomena situasi dimana fenomena itu berada. Penelitian kualitatatif merupakan fokus perhatian dengan beragam metode yang mencakup pendekatan interaktif dan naturalistik terhadap subjek penelitiannya, dalam arti penelitian kualitatif mempelajari benda didalam konteks alamiahnya yang berupaya untuk memahami atau menafsirkan fenomena yang dilihat dari sisi makna yang dilekatkan pada manusia (peneliti) kepadanya, (Denzim dalam pantilima, 2011). Tujuan penelitian kualitatif untuk menemukan pola-pola yang mungkin dapat dikembangkan menjadi teori. Teori ini mendapat bentuk berdasar dari analisis data yang kian bertambah sepanjang berlangsungnya penelitian.

\section{PEMBAHASAN}

\section{Fungsi Bangunan}

Sebagian besar bangunan di kawasan studi telah mengalami perubahan fungsi dari rumah tinggal menjadi tempat usaha, toko, dan kantor. Kantor menjadi hotel, Mess AL menjadi tempat usaha, toko, warung, jasa, dan rumah tinggal menjadi tempat area parkir.

Bangunan bersejarah dengan posisi yang cukup dominan difungsikan sebagai area perdagangan.

Pada pertokoan bagian Utara fungsi yang mendominasi adalah perkantoran dan jasa, pada bagian tengah yang mendominasi adalah pertokoan dan rumah makan, bagian Selatan adalah didominasi perkantoran, komersil.

Bangunan bersejarah berubah fungsi (Mess Nala AL menjadi kawasan komersil), sedangkan yang konsisten saat ini adalah SMP Nasional, rumah perwira Kowal AL.

Aktivitas komersil seperti resto / rumah makan, mall, medical centre, toko agung menghidupkan aktivitas kawasan di malam hari.

\section{Activity Support}

Ada berbagai activity support yang didefinisikan oleh penulis antara lain PKL, penarik becak, penjaga parkir, pejalan kaki, angkot dan satpam.

Activity muncul karena adanya aktivitas utama yang menarik pengunjung seperti penjaga parkir, satpam dan polisi.

Seringkali activity support pada kawasan studi menimbulkan masalah seperti parkir kendaraan di bahu jalan, angkutan kota yang berhenti seenaknya, PKL didepan sekolah pada jam tertentu sehingga menghambat sirkulasi yang menyebabkan kemacetan.

\section{Pertumbuhan Koridor}

Pertumbuhan secara fisik sangat tinggi hal ini dapat dilihat bahwa rumah tinggal yang berubah menjadi bangunan tinggi, perkantoran, pertokoan. Mess Nala AL berubah menjadi area komersil seperti warung kopi, apotek, praktek dokter, pegadaian, rumah laundry, kelontong dan toko.

Pertumbuhan vertikal banyak perubahan bangunan yang dulunya rumah tinggal dan toko menjadi perkantoran, hotel dengan bangunan tinggi, serta kantor polisi menjadi mall.

Pertumbuhan horizontal sangat sedikit bahkan cenderung tidak ada karena keterbatasan lahan yang dimiliki.

Pertumbuhan secara ekonomi kawasan studi dilihat bentuk ekonominya (pertokoan) masih berdiri sendiri-sendiri, individual function tidak terkonsep dan terencana baik.

\section{Pergerakan Lalulintas}

Arah Selatan kota depan Bank Muamalat sering terjadi perlambatan kendaraan karena banyaknya nasabah Bank Muamalat memarkir kendaraan di bahu jalan.

Depan SMP Nasional terjadi juga perlambatan kendaraan sampai depan Bursa Cakar karena (1). Pengantar anak sekolah dan anak sekolah memarkir kendaraan dan pergerakan kendaraan siswa. (2). Parkir kendaraan didepan Bursa Cakar menempati bahu jalan karena tidak adanya area parkir bangunan tersebut.

Depan Toko Agung terjadi kemacetan kendaraan akibat banyaknya pengunjung dan memarkir kendaraan di bahu jalan sampai persimpangan lampu merah jalan Ratulangi dengan jalan Kasuari.

Depan Medical Centre terjadi pula kemacetan pergerakan (sirkulasi) lalulintas akibat parkir kendaraan di bahu jalan karena kurangnya tempat parkir yang tidak sebanding dengan pengunjung.

Pergerakan dari Utara depan KFC dan Pizza Hut terjadi pula perlambatan karena sirkulasi pergerakan kendaraan yang keluar dari kedua resto tersebut.

Persimpangan jalan Lanto dg. Pasewang dan jalan Ratulangi depan Hotel Sahid sering pula terjadi perlambatan pergerakan lalulintas akibat pergerakan kendaraan tamu hotel sampai depan Mall Ratu Indah, biasanya terjadi pada malam hari.

\section{KESIMPULAN}

Ruang publik yang dimiliki setiap bangunan yang ada di koridor jalan Ratulangi mempunyai fungsi yang berbeda-beda dan luasan yang berbeda pula, ada yang memilki ada yang tidak memiliki sesuai dengan peruntukan lahannya. Ada yang tertata rapi dan terkonsep dimanfaatkan sesuai dengan fungsinya adapula yang seadanya tidak jelas peruntukannya serta adapula yang multi fungsi penggunaannya.

Activity support yang terjadi disekitar jalan Ratulangi sangat beragam sesuai dengan aktivitas utama yang terjadi setiap bangunan yang ada di koridor jalan Ratulangi yang mampu 


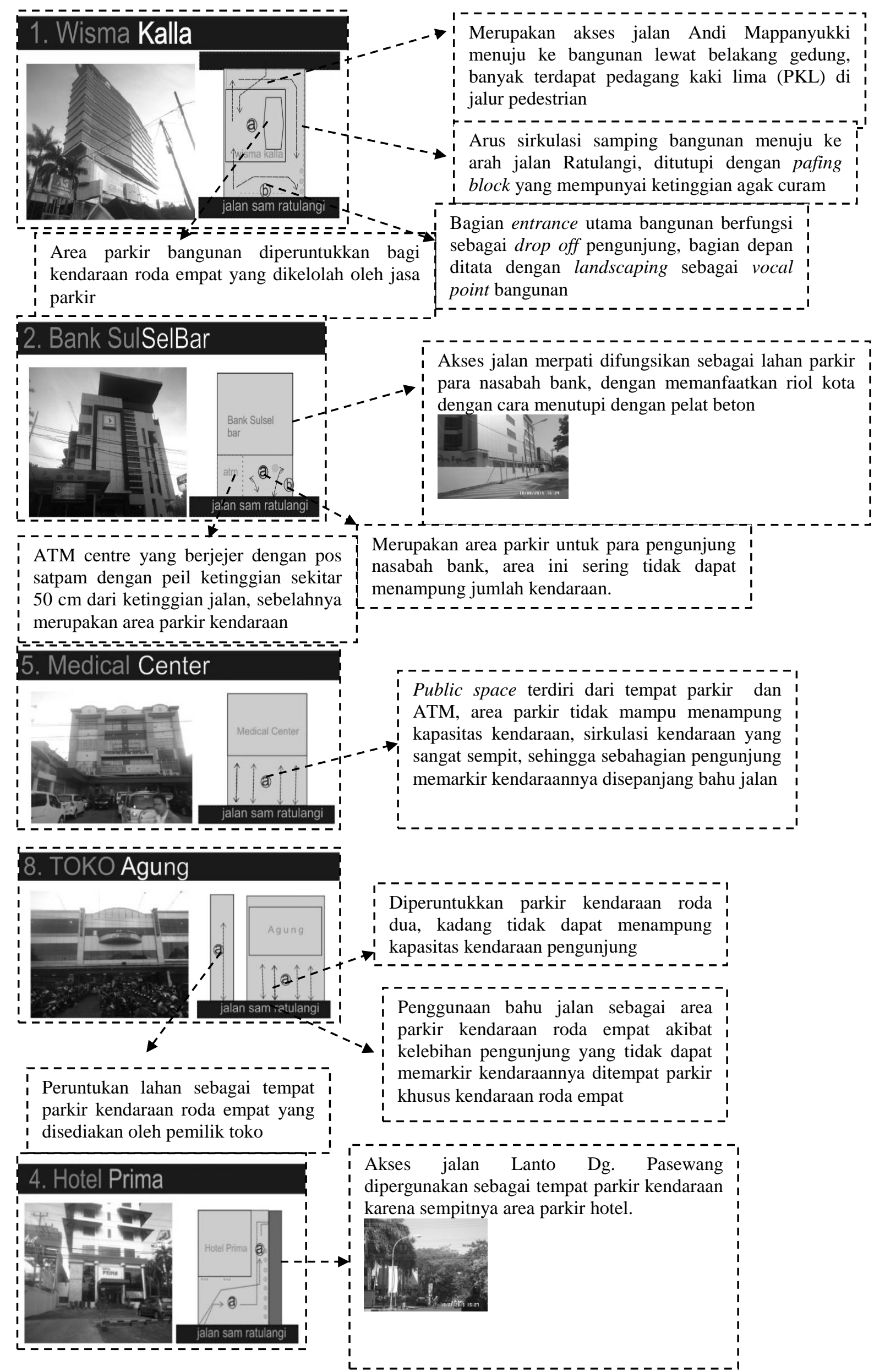




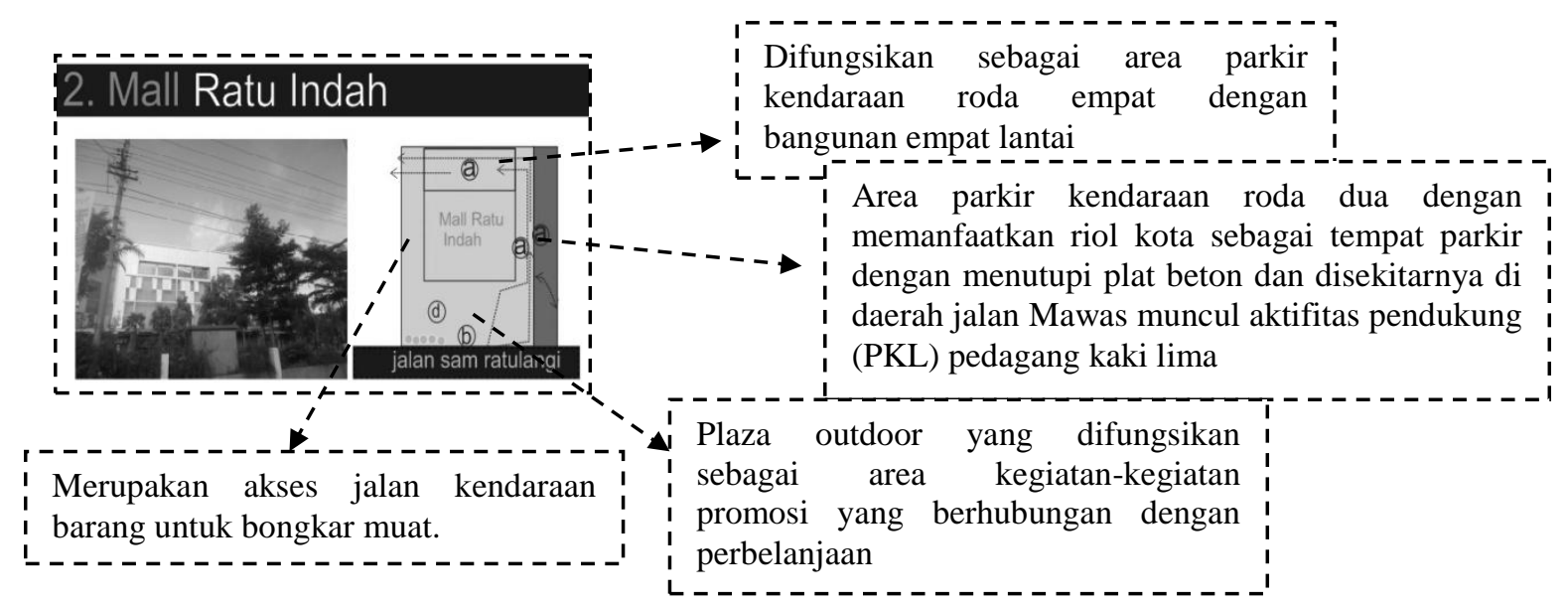

menghubungkan antara bangunan dengan koridor jalan serta permasalahan-permasalahan yang terjadi disepanjang koridor jalan Ratulangi seperti perparkiran, kemacetan dan pergerakan lalulintas.

Pertumbuhan koridor disepanjang jalan Ratulangi sangat beragam dari segi fisik terjadi perubahan-perubahan bangunan dari rumah tinggal menjadi pertokoan, kantor dan komersial, kantor menjadi mall serta mess menjadi area komersial. Dari segi ekonomi kawasan sendiri-sendiri tidak terkonsep dan terencana baik.

Pergerakan lalulintas di koridor ini sangat beragam mulai dari perlambatan hingga kemacetan kendaraan akibat tidak adanya fasilitas parkir di beberapa bangunan dan pergerakan sirkulasi kendaraan yang cukup tinggi di setiap bangunan yang berbeda.

\section{DAFTAR PUSTAKA}

- Ahmadi, 2014, Metode Penelitian Kualitatif, Arruzz Media, Yogyakarta.

- Basuki, 2006, Penelitian Kualitatif Untuk IlmuIlmu Kemanusiaan dan Budaya.

- Denzim dan Lincoln, 2009, Handbook of Qualitative Research, Sage Publication, California USA.

- Denzim dan Lincoln, 2011, Handbook of Qualitative Research 2, Sage Publication, California USA.

- Darmawan, 2006, Teori dan Kajian Ruang Publik Kota, UNDIP, Semarang.

- Darmawan, 2005, Teori dan Kajian Ruang Publik Kota, UNDIP, Semarang.

- Haryanto, 2011, Sirkulasi, Parking and Activity Support Kota Makassar (pendekatan analisa desain), Majalah Ilmiah Al-Jibra, Makassar.

- Miles dan Hubberman, 1992, Qualitative Data Analysis, Univ. Indonesia, Jakarta.

- Moelong, 2002, Metode Penelitian Kualitatif, Remaja Rosdakarya, Bandung.
- Mulyo, 2008, Pengaruh Fungsi Bangunan dan Activity Support Terhadap Perkembangan Koridor, Pascasarjana UNDIP, Semarang.

- Nuzuluddin, 2007, Pengaruh Parkir dan Activity Support Terhadap Sirkulasi Kawasan Petorongan Semarang, Tesis UNDIP, Semarang.

- Patilima, 2011, Metode Penelitian Kualitatif, Alfabeta, Bandung. 